\title{
EL TRIBUNAL DE CUENTAS EUROPEO EN EL TRATADO POR EL QUE SE INSTITUYE UNA CONSTITUCIÓN PARA EUROPA
}

SUSANA RUIZ TARRÍAS 


\section{SUMARIO}

1. Introducción. 2. La configuración del Tribunal de Cuentas Europeo COMO INSTITUCIÓN DE LA UNIÓN EUROPEA. 3. EL STATUS DE LOS MIEMBROS DEL Tribunal de Cuentas Europeo en el Tratado por EL OUE SE INSTITUYE UNA

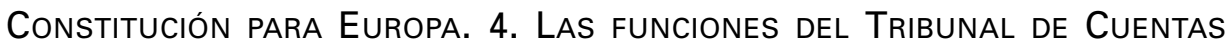
Europeo en El TRATAdo QUE INSTITUYE UNA Constitución PARA EUROPA. 5. CONCLUSIONES. 


\title{
EL TRIBUNAL DE CUENTAS EUROPEO EN EL TRATADO POR EL QUE SE INSTITUYE UNA CONSTITUCIÓN PARA EUROPA
}

POR

\author{
SUSANA RUIZ TARRÍAS \\ Profesora Asociada de Derecho Constitucional \\ Universidad de Almería
}

\section{INTRODUCCIÓN}

Como resulta suficientemente conocido, desde que el concepto "moderno" de Presupuesto apareciera históricamente configurado como un elemento más de la "Constitución inglesa del siglo XVIII", la "idea de Presupuesto" lleva implícita "la idea de Cuenta», una institución que, como subrayaba a principios del siglo XIX E. Corrales Sánchez, podía "en los Gobiernos absolutos restringirse y confundirse con el Poder ejecutivo y el administrativo" pero que, "forzosamente en los Gobiernos representativos ha de adquirir más extenso desarrollo, y cobrando ensanche, poseer verdadera independencia, porque entonces la institución del manejo de los fondos públicos se convierte en función constitucional y en garantía del Poder legislativo ante el ejecutivo»".

1 Corrales SÁnchez, E.: "La institución del Tribunal de Cuentas en España y en el extranjero". Revista General de Legislación y Jurisprudencia, año quincuagésimo, tomo 100, primera parte, p. 242. 
Así será a partir del período de entreguerras, cuando se produzca la incorporación de los órganos de control externo a los Textos Constitucionales en la lógica propia del significado del Estado de Derecho como expresión jurídica de la democracia ${ }^{2}$. Unas premisas que, recogidas por el constitucionalismo posterior a la II Guerra Mundial explican, a juicio de P. Lucas Verdú, "que las Cartas fundamentales modernas se preocupen de establecer sus principios básicos y que incorporen el Tribunal de Cuentas a su articulado» ${ }^{3}$.

De ahí que E. Eseverri Martínez haya podido afirmar, con carácter general, que aunque todos los Estados, "cualquiera que sea su esquema de organización política, han sentido la necesidad de arbitrar los mecanismos institucionales precisos para controlar el gasto", esta necesidad "se entiende más inmediata en los Estados de Derecho», en los que «el respeto por la libertad y la transparencia en la gestión pública de sus Gobiernos son exigencias primordiales".

Por ello, la existencia de mecanismos de control del gasto público constituyen una garantía de la ejecución de los programas económicos aprobados por los Parlamentos representativos en las Leyes de Presupuestos e, indirectamente, hacen posible la "credibilidad de los ciudadanos en las actuaciones de los órganos de decisión» ${ }^{4}$.

En este sentido, resulta sumamente significativo y coherente con toda la tradición en que se insertan las afirmaciones anteriores que autores como I. Harden, F. White y K. Donnelly hayan constatado que a medida que la Unión Europea "gasta más, o mucho más", los contribuyentes europeos y los votantes están menos predispuestos a aceptar su legitimidad sin un fuerte sistema de control financiero y contable ${ }^{5}$,

Sin embargo, el Tribunal de Cuentas Europeo, afirma J. Inghelram, es una «joven» y reciente institución de la Unión Europea que ha sufri-

2 Vid. Ruiz TARrías, S.: Presupuesto y Parlamentarismo. La aportación del Presupuesto al parlamentarismo continental europeo. Sevilla, Fundación El Monte, 2003.

3 Lucas Verdú, P.: "Apuntes sobre los aspectos jurídico-políticos del Tribunal de Cuentas", en El Tribunal de Cuentas en España, vol. II, Madrid, Instituto de Estudios Fiscales, 1982, p. 843.

4 ESEVERRI MARTínez, E.: «El control jurídico del gasto público», en VV.AA.: El Tribunal de Cuentas en España, vol. I, Madrid, Instituto de Estudios Fiscales, 1982, p. 481.

5 Harden, I.; White, F., y Donnelly, K.: "The Court of Auditors and Financial Control and Accountability in the European Community", European Public Law, vol. I, Issue 4 , p. 600 . 
do "importantes cambios en la última década» ${ }^{6}$ derivados, como se podrá comprobar en las páginas que siguen, del propio proceso de construcción de la Unión Europea y, especialmente, del progresivo afianzamiento del Parlamento Europeo como órgano representativo entre las instituciones comunitarias.

La intención del presente trabajo, por tanto, no es otra que la de estudiar los caracteres esenciales que presenta el Tribunal de Cuentas Europeo en el Tratado que instituye una Constitución para Europa (en adelante, TICE), tratando de contrastar su actual regulación en el Tratado CE y el principal pronunciamiento, hasta el momento, del Tribunal de Justicia de la Unión Europea sobre las competencias de esta institución europea.

\section{LA CONFIGURACIÓN DEL TRIBUNAL DE CUENTAS EUROPEO COMO INSTITUCIÓN DE LA UNIÓN EUROPEA}

Desde luego, la existencia de un Tribunal de Cuentas Europeo se explica, especialmente, como aprecia S. Flizot, por la evolución en el contenido y la financiación del Presupuesto europeo, de ahí que sea a partir del momento en que las Comunidades Europeas gestionan recursos propios y no sólo "simples contribuciones financieras de los Estados" - circunstancia que tiene lugar con motivo de la firma del Tratado de Luxemburgo, el 22 de abril de 1970_, cuando "se imponga" un reforzamiento del control externo de los ingresos y de los gastos comunitarios ${ }^{7}$.

Más adelante, se hará evidente que la inicial "Comisión de control", cuya misión, según los artículos 206 del Tratado CE, 180 del Tratado CEEA y 78 quinto del Tratado CECA, consistía en "constatar la legalidad y la regularidad de los ingresos y de los gastos y asegurar una buena gestión financiera $\iota^{8}$, no podía desarrollar plenamente el papel de órgano de control debido a "la limitación de sus medios personales" y

6 INGHELRAM, J.: "The European Court of Auditors: Current legal issues», Common Market Law Review, n. ${ }^{\circ}$ 37, 2000, pág. 129.

7 FLIZOT, S.: "Les rapports entre la Cour des Comptes Européenne et les Institutions Supérieures de contrôle des États membres. Quelle application du principe de subsidiarité? Revue du Marché Commun et de I'Union européenne, $\mathrm{n} .^{\circ} 455$, février 2002, p. 114.

8 Parlement Européen: Pour une Cour des Comptes Européenne. Introduction par Heinrich Aigner. Recueil de Documents. Secrétariat Général. Direction Générale de la Recherche et de la Documentation. Septembre, 1973, p. 37. 
a su "dependencia jurídica y material del ejecutivo comunitario». Una deficiencia del sistema de control externo que, en opinión de P. Lelong, si ya era "de por sí grave, devino intolerable cuando el presupuesto comunitario creció en volumen en los términos en que lo hizo durante el decenio 1965-1975 ${ }^{9}$.

En concreto, De Crouy-Chanel, I. y Perron, Ch. subrayan cómo "la evolución del presupuesto y de las normas de financiación de las Comunidades Europeas", así como "el incremento del papel del Parlamento en materia presupuestaria», confluyeron para que en 1975 -a través del "Tratado modificador de determinadas disposiciones financieras comprendidas en los Tratados de creación de las Comunidades Europeas", firmado en Bruselas el 22 de julio de ese año-, se reformara el sistema de control financiero externo y, en última instancia, se creara el Tribunal de Cuentas Europeo.

En efecto, según reconocen los autores mencionados, "en el espacio de diez años, entre 1960 y 1970, los gastos de las Comunidades y de los fondos europeos de desarrollo se multiplicaron por 50". Un aumento "cuantitativo" de los fondos comunitarios que exigía, "naturalmente un reforzamiento de los instrumentos para su control». Al mismo tiempo, el Parlamento Europeo era favorable «al reforzamiento del control financiero externo" en el seno de las Comunidades Europeas y ya en 1964 había propuesto la creación de un Tribunal de Cuentas Europeo ${ }^{10}$.

Hasta la aprobación del Tratado de Bruselas de 22 de julio de 1975, como describe V. Manteca Valdelande, existían dos organismos comunitarios que realizaban funciones de control externo del Presupuesto comunitario: "la Comisión de Control de la C.E.E., de la C.E.C.A. y de la C.E.E.A." y "el Comisario de Cuentas de la C.E.C.A.». La primera de ellas "tenía competencias para realizar el examen de los ingresos y gastos que, con carácter general, se referían a la Comunidad Económica Europea y a la Comunidad Europea de la Energía Atómica y los gastos e ingresos administrativos de la Comunidad Europea del Carbón y del Acero". Por su parte, el "Comisario de Cuentas" de la CECA "tenía como competencia el control de la regularidad de las operaciones contables y de la gestión financiera de la

9 LELONG, P.: «La Cour des Comptes des communautés et le contrôle externe des finances publiques européennes". Revue française de finances publiques, n. ${ }^{\circ} 4$, 1983, p. 100.

10 De Crouy-Chanel, l. et Perron, Ch.: La Cour des comptes européenne. París: Presses Universitarires de France, 1998, pp. 24-26. 
Alta Autoridad con excepción de los gastos e ingresos administrativos" ${ }^{11}$.

A tales efectos, el antiguo artículo 206 del Tratado de Roma, donde se regulaba la "Comisión de Control», fue sustituido por los artículos 206 , 206bis y 206ter, al tiempo que se adaptaban los contenidos de los Tratados CECA (artículos 78, sexto; 78, séptimo y 78, noveno) y CEEA (artículos180, 180bis y 183).

En tales preceptos, a pesar de la opción por la denominación de "Tribunal", el Tribunal de Cuentas Europeo era configurado como una institución "desprovista de toda competencia jurisdiccional»" ${ }^{12}$ siguiendo, de este modo, uno de los "modelos" de control financiero, el proveniente de Gran Bretaña, Irlanda, Dinamarca, Suecia, Finlandia y Austria, dado que, como han subrayado I. Harden, F. White y K.Donnelly, no se puede considerar que exista un «modelo continental unificado de control financiero" en cuyo contexto pudiera situarse el Tribunal de Cuentas Europeo ${ }^{13}$.

En efecto, en la actualidad suele ser común configurar como específico entre los órganos de control externo al "sistema anglosajón", vigente en los países que siguen la "tradición constitucional inglesa" del "common law", cuyas instituciones fiscalizadoras presentan singularidades respecto del "régimen contable», tanto en lo que se refiere al "régimen de control de fondos en el Consolidated Fund Service» como a las "funciones del Comptroller and Auditor General".

De otro lado se identifica el "sistema francés o iberoamericano", cuya característica esencial consiste en el desarrollo de "una fiscalización jurisdiccional sobre los cuentadantes" que incluye la "potestad" para dictar "sentencia", y en cuyo ámbito se incluiría el Tribunal de Cuentas italiano, pero cuyo "modelo" por antonomasia lo constituye el sistema establecido por la Corte de Cuentas francesa.

11 Manteca Valdelande, V.: "El Tribunal de Cuentas Europeo, una institución comunitaria de control». Noticias de la Unión Europea, n. ${ }^{\circ}$ 197, 2001, pp. 21-22. (En el mismo sentido, vid. LeLONG, P.: "La Cour des Comptes et les contrôles financiers dans la Communauté européenne", Revue française de comptabilité, n. ${ }^{\circ} 130,1982$, pp. 502-510).

12 FLIzOT, S.: "Les rapports entre la Cour des Comptes Européenne et les Institutions Supérieures de contrôle des États membres. Quelle application du principe de subsidiarité?", op. cit., p. 114, nota 14.

${ }^{13}$ HaRden, I.; White, F., y Donnelly, K.: "The Court of Auditors and Financial Control and Accountability in the European Community». European Public Law, vol. I, Issue 4,1995 , p. 601 . 
Otro sistema de control externo diferenciado es el "germano-escandinavo", en el que se incluiría, entre otros, el Tribunal Federal de Cuentas alemán, cuya característica más relevante proviene de la "estrecha" conexión que tales órganos de control externo mantienen con el respectivo Parlamento, hasta el punto de que, en ocasiones, los primeros constituyen simples órganos de éste, del que reciben «directrices e instrucciones". Se trata de órganos que carecen de "potestades para sentenciar judicialmente" y de "facultades imperativas", de tal modo que sus criterios "no tiene otra posibilidad de imponerse que la de ser acogidos por el Parlamento, que podrá obligar al Gobierno a corregir las deficiencias observadas ${ }^{14}$.

En todo caso, como constataba H. Marty-Gauquié, el «modelo jurisdiccional" no constituía el modelo más extendido en el seno de los Estados miembros y, de cualquier modo, a este "control jurisdiccional» se superpone un "control administrativo" de las cuentas que, de hecho, "constituye la actividad esencial de estas instituciones». Por ello, afirmaba, mientras que los "ordenamientos jurídicos nacionales gobernados por la concepción latina del derecho han investido a sus Tribunales de Cuentas de competencias jurisdiccionales" (Francia, Italia, Bélgica, Luxemburgo y Países Bajos), "todos los Estados denominados de la Europa del Norte únicamente han dotado a sus instituciones superiores de control de competencias administrativas de control», incluso cuando la denominación de estos órganos utiliza en la mayoría de los casos, aunque no exclusivamente, el término "Tribunal» ${ }^{15}$, como ocurre con el Reino Unido, Dinamarca e, Irlanda.

En este contexto, el Tribunal de Cuentas Europeo comenzó a funcionar en $1977^{16}$, después de concluir el proceso de ratificación del Tratado firmado en Bruselas en 1975, iniciando, en opinión de De Crouy-Chanel, I. y Perron, Ch., "una etapa decisiva en el proceso de emancipación del control externo de las finanzas comunitarias", tanto en su dimensión "política" como "técnica».

14 Nofuentes, M.: «Sistemas institucionales de control en el Derecho comparado». Crónica 1981. Primer volumen, II Encuentros del Tribunal. Madrid, Tribunal de Cuentas, 1982, pp. 467-470.

${ }^{15}$ MARTY-GauQUiÉ, H.: Le controle externe des Finances Publiques Européennes. Bruxelles, Editions Labor, 1988, p. 74.

16 P. LELONG afirma que la primera sesión que celebró el Tribunal de Cuentas de las Comunidades Europeas tuvo lugar el 25 de octubre de 1977 ("La Cour des comptes des Communautés européennes: sa misión, son bilan", Les Cahiers du fédéralisme, n. ${ }^{\circ} 274,1989$, p. 37). 
De un lado, afirmaban los autores precitados, el Parlamento disponía de las competencias que le permitían desarrollar "un control en profundidad de la ejecución del presupuesto comunitario" y, de otro, podía "apoyarse" en un órgano que aparecía, "por su estatuto y sus medios de actuación", como un "actor verdaderamente nuevo" en la escena institucional ${ }^{17}$, de manera que si bien el Tratado firmado en Bruselas en 1975 no reconocía al Tribunal de Cuentas Europeo la naturaleza de «institución» de las Comunidades Europeas, "una declaración anexa" a dicho documento "preveía la modificación de las disposiciones necesarias" del Reglamento Financiero y del Estatuto de Funcionarios con el fin de "asimilarlo expresamente a una institución en la aplicación de estos textos».

De hecho, tales previsiones se concretaron en la revisión del Reglamento financiero de 21 de diciembre de 1977, que reconocía al Tribunal de Cuentas una "completa autonomía de gestión sobre el plan presupuestario y administrativo", según los términos en que se admitía a las instituciones comuntiarias "creadas por los tratados constitutivos", por lo que, en opinión de los autores precitados, quedaba convertido en una "cuasi-institución»" ${ }^{18}$.

Asimismo, al igual que sucedía con las instituciones comunitarias, el Tribunal de Cuentas Europeo gozaba también del poder de «dotarse de un reglamento de régimen interior sin intervención extraña alguna» ${ }^{19}$.

En todo caso, será el Tratado de la Unión Europea, firmado en Maastricht el 7 de febrero de 1992, quien eleve "formalmente" al Tribunal de Cuentas Europeo al rango de «institución» de la Unión Europea, situándolo al mismo nivel que el Parlamento, el Consejo, la Comisión y el Tribunal de Justicia. Una configuración que sería mantenida, posteriormente, por el Tratado de Ámsterdam, firmado el 2 de octubre de $1997^{20}$

17 De Crouy-Chanel, l. et Perron, Ch.: "La Cour des comptes européenne», op. cit., p. 31.

${ }^{18}$ De Crouy-Chanel, I. et Perron, Ch.: "La Cour des comptes européenne», op. cit., p. 30.

19 Bugnot, P.: «El Tribunal de Cuentas de las Comunidades Europeas: Balance provisional", Presupuesto y Gasto Público, n. ${ }^{\circ} 15,1983$, p. 221.

20 Tratado de Ámsterdam y versiones consolidadas de los Tratados de la Unión Europea y de la Comunidad Europea. Preparación de la edición y Estado preliminar por Ricardo Alonso GaRCía. Madrid, Civitas, 1998.

21 Ley Orgánica 3/2001, de 6 de noviembre, por la que se autoriza la ratificación por España del Tratado de Niza por el que se modifican el Tratado de la Unión Europea, los Tratados Constitutivos de las Comunidades Europeas y determinados actos conexos, firmado en Niza el día 26 de febrero de 2001 (BOE n. ${ }^{\circ} 267$, de 7 de noviembre). 
y por el Tratado de Niza, firmado el 26 de febrero de $2001^{21}$ y que, en última instancia, también se recoge expresamente en el artículo I-31, apartado primero, del Tratado por el que se instituye una Constitución para Europa ${ }^{22}$.

\section{EL STATUS DE LOS MIEMBROS DEL TRIBUNAL DE CUENTAS EUROPEO EN EL TRATADO POR EL QUE SE INSTITUYE UNA CONSTITUCIÓN PARA EUROPA}

La preocupación por la independencia del órgano de control externo de las cuentas europeas se encontraba en su mismo origen cuando, como se ha señalado, en el Tratado firmado en Bruselas en 1975 se creaba el Tribunal de Cuentas Europeo, dado que si bien no era reconocido como una institución de la Comunidad Económica Europea, se le atribuían facultades típicas de las instituciones europeas, como las de dotarse de un reglamento de régimen interior y disfrutar de una completa autonomía de gestión sobre el plan presupuestario y administrativo.

Precisamente el apartado cuarto, in fine, del artículo III-384 del TICE reconoce que el Tribunal de Cuentas «adoptará su Reglamento Interno", que "se someterá a la aprobación del Consejo", debiendo destacarse la ausencia en esta redacción de una referencia a la mayoría requerida para la aprobación por el Consejo, cuando en el artículo 248.4, in fine, del Tratado CE, según la reforma introducida por el Tratado de Niza, se prevé la elaboración del Reglamento Interno y la posterior aprobación por la «mayoría cualificada» del Consejo.

En todo caso, el Tratado que instituye una Constitución para Europa trata de mantener y profundizar los rasgos que han venido caracterizando hasta el momento al Tribunal de Cuentas Europeo a partir de su definición, taxativamente, como una «institución», en el apartado primero del artículo I-31, perfilando las características de «independencia» y "colegialidad" ya consagradas en el artículo 247 del Tratado CE, según la versión consolidada en el Tratado de Ámsterdam.

En el primero de los sentidos, el apartado tercero del artículo l-31 - con unos contenidos muy similares a los vigentes ya en la versión de Amsterdam-, afirma que sus miembros ejercerán sus funciones "con plena independencia, en interés general de la Unión", a cuyos efectos en el apartado primero del artículo III-385 se les exige que "deberán

22 Diario Oficial de la Unión Europea, n. ${ }^{\circ}$ C 310, de 16 de diciembre de 2004. 
ofrecer plenas garantías de independencia», requiriéndose, como garantía de competencia profesional, que sean "elegidos de entre personalidades que pertenezcan o hayan pertenecido en sus respectivos Estados a las instituciones de control externo o que estén especialmente cualificadas para esta función", mientras que en el apartado tercero del mismo precepto se establece que «en el desempeño de sus funciones, los miembros del Tribunal de Cuentas no solicitarán ni aceptarán instrucciones de ningún Gobierno ni de ningún organismo" y "se abstendrán de todo acto incompatible con sus funciones".

Unas cautelas que se han de entender en relación con su origen, en tanto que el artículo I-31 del TICE dispone, en su apartado tercero - recogiendo las modificaciones introducidas en el Tratado de Niza-, que el Tribunal de Cuentas "estará compuesto por un nacional de cada Estado miembro", pero también con el proceso seguido para el nombramiento de sus miembros, dado que el apartado segundo del artículo III-385 se remite a una "lista de miembros establecida de conformidad con las propuestas presentadas por cada Estado miembro" - como recoge la reforma del Tratado de Niza-, elaborada por el Consejo "mediante decisión europea» y sobre la que se pronunciará "previa consulta al Parlamento europeo".

En particular, se ha de subrayar que el apartado tercero del artículo 247 del Tratado CE en la versión consolidada de Ámsterdam exigía "unanimidad" al Consejo, previa consulta al Parlamento Europeo, para la elaboración de la lista de miembros, mientras que la reforma de dicho precepto por el Tratado de Niza redujo la exigencia a una «mayoría cualificada», también previa consulta al Parlamento Europeo. EI TICE reconoce el rango de "decisión europea" al acto del Consejo de elaboración de la lista de miembros, previa consulta al Parlamento Europeo, un "acto jurídico" de la Unión, de carácter "no legislativo" pero "obligatorio en todos sus elementos" (párrafo, apartado 1, art. l-33 del TICE).

En todo caso, como parece lógico, los medios personales al servicio del Tribunal de Cuentas Europeo se han ido incrementando progresivamente desde su creación ${ }^{23}$, al tiempo que se ha mantenido una política de diversificación en los orígenes "profesionales" y "geográficos"

23 Según constatan De Crouy-Chanel, l, y Perron, Ch., la progresión en medios humanos ha sido de 164 personas en 1978, 214 en 1979, 294 en 1979, 294 en 1982, 307 en 1985 y 500 personas en 1997 ( "La Cour des Comptes Européenne», op. cit., p. 61). Un incremento de personal que en el año 2004 se elevaba en 509 puestos fijos y 96 temporales (Diario Oficial de la Unión Europea, I/109, de 23 de febrero de 2004). 
de su personal, introduciendo elementos de cohesión a través del desarrollo de programas "de formación profesional" que proporcionen a los auditores una formación "técnica común", sin perjuicio de sus "propias experiencias profesionales». En última instancia, afirman De Crouy-Chanel, I y Perron, Ch., para evitar la influencia excesiva de las técnicas y métodos propios del sistema de control externo de los países de origen, el Tribunal de Cuentas ha venido Ilevando a cabo, "deliberadamente", una "mezcla de nacionalidades en cada uno de los servicios» ${ }^{24}$.

Por lo demás, el tiempo de mandato, seis años, y la posibilidad de renovación del mismo cierran el conjunto de garantías de independencia de los miembros del Tribunal de Cuentas Europeo, unos contenidos prácticamente idénticos a los ya existentes en la versión consolidada de Ámsterdam del Tratado CE, asegurando el apartado quinto del artículo III-385 del TICE que salvo en los casos de renovación periódica y fallecimiento, el mandato de sus miembros concluirá individualmente sólo en los casos de «dimisión voluntaria o destitución declarada por el Tribunal de Justicia», a instancias del Tribunal de Cuentas. El Tribunal de Justicia, se afirma en el apartado sexto del mismo precepto del TICE, es la única instancia que podrá «relevar» de sus funciones o "privar" de su "derecho a la pensión, o de cualquier otro beneficio sustitutivo" a los miembros del Tribunal de Cuentas, "declarando" que "dejan de reunir las condiciones requeridas o de cumplir las obligaciones derivadas de su cargo".

A tales efectos, el artículo 4 del nuevo Reglamento Interno del Tribunal de Cuentas Europeo, adoptado por el Tribunal el 8 de diciembre de 2004, previa aprobación del Consejo, y que ha entrado en vigor el 1 de enero de $2005^{25}$, regula pormenorizadamente las circunstancias de "cese y privación del derecho a la pensión o de cualquier otro beneficio", estableciendo un procedimiento en el que se recoge la participación del "miembro afectado»"

${ }^{24}$ De Crouy-Chanel, I., y Perron, Ch.: "La Cour des Comptes Européenne», op. cit., p. 62.

25 Diario Oficial de la Unión Europea, L-18, de 20 de enero de 2005, pp. 1 a 8.

La entrada en vigor del Reglamento se ha producido junto a la de una serie de Disposiciones de Aplicación del Reglamento Interno, aprobadas por la Decisión n. ${ }^{\circ}$ 92-2004, publicadas, por mandato expreso de la propia Decisión, en la página web del Tribunal de Cuentas Europeo (Vid. http://eca.eu.int/eca/rules/docs/modalites es.pdf).

${ }^{26}$ A tal efecto dispone que "cuando el Tribunal estime, por mayoría de sus miembros, que de la información que le haya sido comunicada se puede deducir que un miembro ha dejado de reunir las condiciones requeridas o de cumplir las 
En caso de "destitución» declarada por el Tribunal de Justicia en tales términos, afirma el artículo III-385, apartado quinto, in fine, del TICE que los interesados serán "sustituidos" por el tiempo restante de su mandato, de manera que salvo en caso de «destitución, los miembros del Tribunal de Cuentas permanecerán en su cargo hasta su sustitución».

Además, también como garantía de independencia, el apartado cuarto del mismo precepto prohíbe el ejercicio, "mientras dure su mandato", de ninguna otra actividad profesional, retribuida o no. Asimismo, prescribe que al asumir sus funciones, "se comprometerán solemnemente a respetar, mientras dure su mandato y aun después de finalizar éste, las obligaciones derivadas de su cargo, en particular, los deberes de integridad y discreción en cuanto a la aceptación, una vez terminado su mandato, de determinadas funciones o beneficios", en una redacción casi idéntica a la ya contenida en el apartado quinto del artículo 247 del Tratado CE en su versión consolidada en Ámsterdam.

No obstante, resulta significativo señalar que el artículo III-385 del TICE no recoge un contenido similar al del vigente artículo 247.8 del Tratado CE, donde se exige "mayoría cualificada" del Consejo para fijar las condiciones de empleo de los miembros del Tribunal, así como los sueldos, dietas, pensiones y "cualesquiera otros emolumentos de carácter retributivo", como tampoco reconoce, como hace el apartado noveno del mismo precepto, que "las disposiciones del Protocolo sobre privilegios y las inmunidades de las Comunidades Europeas aplicables a los jueces del Tribunal de Justicia serán igualmente aplicables a los miembros del Tribunal de Cuentas".

obligaciones que dimanan de su cargo (apartado 7 del artículo 247 del Tratado CE y apartado 7 del artículo $160 \mathrm{~B}$ del Tratado CEEA), encargará al Presidente o, si fuese el Presidente el miembro afectado, al miembro que ocupe el siguiente lugar en el orden de prelación en virtud del artículo 5 del presente Reglamento, la preparación de un informe preliminar" (apartado 1). Dicho informe preliminar "se comunicará, acompañado de los documentos justificativos, a todos los miembros, incluido el miembro afectado, que a su vez comunicará como respuesta sus observaciones escritas en un plazo razonable fijado por el Presidente o, si fuese el Presidente el miembro afectado, por el miembro que ocupe el siguiente lugar en el orden de prelación»(apartado 2). El miembro afectado "también será invitado a presentar oralmente sus explicaciones ante el Tribunal» (apartado 3).

De cualquier manera, "la decisión de presentar el caso ante el Tribunal de Justicia para destituir de su cargo al miembro afectado o privarle del derecho a la pensión o de cualquier otro beneficio se adoptará, mediante votación secreta, por mayoría de cuatro quintas partes de los miembros del Tribunal", sin que el miembro afectado pueda participar en la votación (apartado 4). 
De hecho, el silencio en relación con este último aspecto por parte del artículo III-385 del TICE contrasta con el reconocimiento expreso en el artículo III-381 de que "el Estatuto del Tribunal de Justicia de la Unión Europea se establecerá en un Protocolo».

De otra parte, es en el artículo 1 del Reglamento Interno del Tribunal de Cuentas donde se consagra la otra característica que antes se mencionaba, la "colegialidad", al disponer que "el Tribunal estará organizado y actuará colegiadamente, de conformidad con lo dispuesto en los Tratados y en el Reglamento financiero ${ }^{27}$ y según las normas del presente Reglamento Interno".

Un Tribunal que, conforme a lo establecido en el apartado segundo del artículo III-385 del TICE tendrá un Presidente elegido de entre sus miembros por un periodo de tres años, con un mandato también renovable -en términos idénticos a lo ya contemplado en la versión consolidada de Ámsterdam del Tratado CE-, previéndose en el artículo 7 del Reglamento Interno que se procederá a la elección del nuevo Presidente "antes de que termine el mandato del Presidente en ejercicio", aunque, en el caso de que el fin del mandato "coincida con la renovación parcial de los miembros realizada de conformidad con el apartado 3 del artículo 247 del Tratado CE y el apartado 3 del artículo 160 B del Tratado CEEA» ${ }^{28}$, la elección "tendrá lugar inmediatamente

27 El Reglamento financiero aplicable al Presupuesto general de las Comunida-

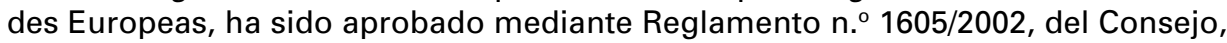
de 25 de junio (Diario Oficial de las Comunidades Europeas, L-248/1, de 16 de septiembre de 2002).

${ }_{28}$ El artículo 247, apartado 3 del Tratado CE, modificado por el artículo 2.36 del Tratado de Niza, establece: «Los miembros del Tribunal de Cuentas serán nombrados para un periodo de seis años. El Consejo, por mayoría cualificada y previa consulta al Parlamento Europeo, adoptará la lista de miembros establecida de conformidad con las propuestas presentadas por cada Estado miembro. El mandato de los miembros del Tribunal de Cuentas será renovable.

Los miembros elegirán de entre ellos al Presidente del Tribunal de Cuentas. Su mandato será renovable».

Por su parte, el apartado 3 del artículo 160 del Tratado CEEA afirma: "Los miembros del Tribunal de Cuentas serán nombrados por un periodo de seis años por el Consejo, por unanimidad, previa consulta al Parlamento Europeo.

Sin embargo, al proceder los primeros nombramientos, cuatro miembros del Tribunal de Cuentas, designados por sorteo, recibirán mandato de cuatro años solamente.

Los miembros del Tribunal de Cuentas podrán ser nuevamente designados.

Los miembros elegirán de entre ellos al Presidente del Tribunal de Cuentas por un periodo de tres años. Su mandato será renovable». 
después y en el plazo máximo de quince días laborables contados a partir de la entrada en funciones del Tribunal en su nueva composición".

El Presidente del Tribunal será elegido "mediante votación secreta", siendo elegido el candidato que obtenga en la primera vuelta "las dos terceras partes de los votos de los miembros del Tribunal». Si ningún candidato alcanzase dicha mayoría, será elegido, en segunda votación, "el candidato que haya obtenido la mayoría de votos de los miembros del Tribunal». En caso de que ningún candidato alcanzase la mayoría mencionada en segunda votación, "se organizarán otras votaciones según el procedimiento fijado en las disposiciones de aplicación ${ }^{29}$.

En todo caso, el Reglamento Interno del Tribunal de Cuentas contempla la creación de "Grupos de Fiscalización" y "Comités". Los primeros tendrán como finalidad «preparar la aprobación por el Tribunal de documentos en materia de fiscalización" (artículo 10) mientras que los segundos "tendrán como finalidad tratar las materias que no sean abordadas por los grupos de fiscalización» (artículo11).

Asimismo, el Tribunal de Cuentas «nombrará» su Secretario General «mediante votación secreta conforme al procedimiento fijado en las disposiciones de aplicación». El Secretario General será responsable "de la gestión del personal y de la administración del Tribunal», respondiendo del ejercicio de sus funciones ante el Tribunal y dando cuenta periódicamente al mismo del desempeño de sus funciones" (artículo 12 del Reglamento).

\section{LAS FUNCIONES DEL TRIBUNAL DE CUENTAS EUROPEO EN EL TRATADO QUE INSTITUYE UNA CONSTITUCIÓN PARA EUROPA}

a) Contenido y objeto de la función fiscalizadora.

Al igual que sucede en el vigente Tratado CE, el Tratado que instituye una Constitución para Europa atribuye al Tribunal de Cuentas Europeo dos clases de funciones: fiscalizadoras y consultivas. No obstante, tal y como se desprende de la regulación de las funciones del Tribunal de Cuentas en el TICE, la fiscalizadora es la que se configura como "función por excelencia» del Tribunal de Cuentas.

29 Vid. Artículo 8 de las Disposiciones de aplicación del Reglamento Interno del Tribunal de Cuentas, adoptadas el 8 de diciembre de 2004. 
Una función definida por V. Manteca Valdelande a partir de la regulación contenida en el Tratado CE, como el ejercicio de "un control sobre los ingresos y gastos comunitarios" con carácter "externo", "independiente", y "a posteriori de su realización", que tiene por objeto "la legalidad", "la regularidad" y "la buena gestión financiera" ${ }^{30}$.

En este sentido, el artículo I-31 del TICE afirma expresamente que el Tribunal "efectuará el control de cuentas de la Unión" (apartado 1). A tales efectos, "examinará las cuentas de la totalidad de los ingresos y gastos de la Unión y garantizará una buena gestión financiera" (apartado 2).

En ejercicio de esta función, según dispone el artículo III-384 - cuya redacción coincide, en términos globales, con el artículo 248 del Tratado CE tras la reforma introducida en el mismo por el Tratado de Niza-, el Tribunal de Cuentas Europeo examinará las cuentas de la totalidad de los ingresos y gastos "de la Unión" y de "cualquier órgano u organismo creado por la Unión en la medida en que el acto por el que se cree ese órgano u organismo no excluya dicho examen" (apartado 1).

Este examen de las cuentas por parte del Tribunal tiene como finalidad comprobar la "legalidad y regularidad" de los ingresos y gastos y garantizar una "buena gestión financiera», informando, en particular, "de cualquier irregularidad".

En concreto, el apartado segundo del artículo III-384 - que coincide prácticamente en todos sus contenidos con los que ya recoge el apartado segundo del artículo 248 del Tratado CE en su versión consolidada en Amsterdam-, precisa que el control de los ingresos "se efectuará a partir de las liquidaciones y las cantidades entregadas a la Unión", mientras que el control de los gastos "se efectuará a partir de los compromisos asumidos y los pagos realizados». En todo caso, ambos controles podrán efectuarse "antes del cierre de las cuentas del ejercicio presupuestario considerado".

El objeto del control también se mantiene en los mismos términos que lo define el vigente apartado tercero del artículo 248 del Tratado CE, al afirmar que está constituido por la "documentación contable» y, en caso necesario, se desarrollará "en las dependencias correspondientes de las otras instituciones, así como en las dependencias de cualquier órgano $u$ organismo que gestione ingresos o gastos en nombre de la Unión y en los Estados miembros, incluidas las dependencias de cualquier persona física o jurídica que perciba fondos del Presupuesto".

30 Manteca Valdelande, V.: «El Tribunal de Cuentas Europeo. Una institución comunitaria de control», op. cit., p. 24. 
Cuando el control deba efectuarse en los Estados miembros, se desarrollará uen colaboración con las instituciones nacionales de control o, si éstas no poseen las competencias necesarias, con los servicios nacionales competentes". A tales efectos, se dispone que el Tribunal y las instituciones nacionales de control de los Estados miembros "cooperarán con espíritu de confianza y respetando su independencia», debiendo comunicar las instituciones o servicios nacionales al Tribunal de Cuentas Europeo «si tienen la intención de participar en el mencionado control».

Esta "colaboración» del Tribunal de Cuentas Europeo con las instituciones de control nacionales para el caso de que el control deba efectuarse en los Estados miembros, se encuentra también prevista en el artículo 248.3 del Tratado $C E$, utilizándose, asimismo, ahora, el término "colaboración», que para P. Lelong constituía una "definición imprecisa $"{ }^{31}$ pero que, en todo caso, ha llevado al Tribunal de Cuentas Europeo, desde 1977, a mantener estrechas relaciones con los organismos nacionales a través de diferentes vías, entre las que se encuentran los "contactos multilaterales bajo la forma de reuniones semestrales" con los Presidentes de los organismos nacionales o agentes designados por ellos, así como "múltiples contactos bilaterales»"

Un modelo de relaciones con las instituciones nacionales de control que, al ser reproducido en el Tratado por el que se instituye una Constitución para Europa, mantiene la duda expresada por Harden, l; White, F. y Donnelly, K., respecto a la posibilidad de que el Tribunal de Cuentas Europeo upueda hacer uso del trabajo de auditoria desarrollado por las propias instituciones nacionales de control", habida cuenta de "las diferencias que existen en el status y competencias" de las mismas ${ }^{33}$.

31 Una «imprecisión» que se ha visto agravada a partir de las distintas traducciones que dicho término ha recibido. Así, según subraya A. LóPEZ DíAZ, «partiendo de las redacciones alemana y francesa" (donde el término "colaboración" fue traducido, respectivamente, como "in Verbundung mit» y "liaison", es posible considerar que el Tribunal de Cuentas Europeo "goza de un poder autónomo para el control», mientras que la "colaboración" reconocida en los "textos italiano y español pudiera dar a entender que existe una especie de derecho de veto de los órganos de control nacional que impedirían que éste se llevase a cabo sin su colaboración» («El control del gasto público comunitario. Relaciones entre Comunidades Autónomas, Estado y Comunidades Europeas", Revista de Derecho Financiero y Hacienda Pública, n. ${ }^{\circ} 243,1997$, p. 197).

32 LELONG, P.:"La Cour des comptes des Communautés européennes: sa misión, son bilan", Les Cahiers du Féderalisme, n. ${ }^{\circ} 274$, 1989, pp. 36-37.

${ }^{3}$ HaRden, I.; White, F., y Donnelly, K.: "The Court of Auditors and Financial Control and Accountability in the European Community", op. cit., p. 613. 
No obstante, en el contexto de la relación con las instituciones fiscalizadoras de los Estados miembros, el Tribunal de Cuentas Europeo ha aprobado las "Directrices de Aplicación Europea de las Normas de Auditoría de la INTOSAl", elaboradas a petición del comité de contacto de los Presidentes de las Instituciones Fiscalizadoras Superiores (EFS) de la Unión Europea, y que representan, según afirma el Prólogo de las mismas, "un magnífico ejemplo de la colaboración cada vez más estrecha entre las EFS de la Unión Europea en temas de interés común ${ }^{34}$.

Por otra parte, como es conocido, la INTOSAI (Organización Internacional de las Entidades Fiscalizadoras Supremas) aprobó en el IX Congreso celebrado en Lima (Perú), en 1977, la denominada Declaración de Lima, donde se recogen las "Líneas Básicas de la Fiscalización", que constituye el fundamento de la auditoría de las finanzas públicas y sirve de marco "filosófico y conceptual" al trabajo de dicha Organización Internacional ${ }^{35}$.

En cualquier caso, según el mencionado apartado tercero del artículo III-384 del TICE, en una redacción que en términos globales coincide con la recogida en el vigente apartado tercero del artículo 248 del Tratado CE, las "instituciones" y "organismos» que gestionen ingresos o gastos en nombre de la Unión, así como «cualquier persona física o jurídica" que perciba fondos del Presupuesto, y las «instituciones nacionales de control» o, en el caso de que éstas no tuvieran las competencias necesarias, "los servicios nacionales competentes", comunicarán al Tribunal, "a instancia de éste, cualquier documento o información necesario para el cumplimiento de su función».

Del mismo modo, también se sigue previendo, con carácter excepcional, que el derecho de acceso del Tribunal de Cuentas Europeo a las informaciones que posea el Banco Europeo de Inversiones respecto de su gestión de los ingresos y gastos de la Unión, "se regirá por un acuerdo celebrado entre el Tribunal de Cuentas, el Banco y la Comisión", y que, a falta de dicho acuerdo, el Tribunal de Cuentas "tendrá, no obstante, acceso a las informaciones necesarias para el control de los ingresos y gastos de la Unión gestionados por el Banco".

Por lo demás, como resulta habitual en los órganos encargados del control externo, esta labor fiscalizadora del Tribunal de Cuentas Europeo tiene como referencia la previa elaboración de unas líneas o planes de fiscalización $y$, en este sentido, con el fin de «exponer en un

${ }^{34}$ Vid. http://www.eca.eu.int/audit_approach/guidelines/docs/intosai-es.pdf.
${ }_{35}$ Vid. http://www.intosai.org/Level2/2_LIMADs.html. 
único documento los principios en los que se basa la planificación, la ejecución y la elaboración de los informes de sus fiscalizaciones", el Tribunal de Cuentas Europeo ha adoptado un documento relativo a las "Políticas y normas de auditoría del Tribunal", que vienen a codificar unos "métodos de trabajo" que han ido evolucionando durante los veinte años que han transcurrido desde la creación de dicha institución.

Dichas políticas se basan en «las mejores prácticas internacionales, representadas por las normas de auditoría" publicadas por la Organización Internacional de Entidades Fiscalizadoras Superiores (INTOSAI) y las normas internacionales de fiscalización establecidas por el Comité Internacional de Prácticas de Fiscalización de la Federación Internacional de Expertos Contables (IFAC), aunque "adaptadas" para tener en cuenta la "misión" y las "responsabilidades" particulares del Tribunal de Cuentas Europeo definidas en el Tratado CE y en el Reglamento Financiero, así como las "particularidades" del contexto comunitario.

Estas "políticas y normas de auditoría" definen los principios básicos que regulan el trabajo del Tribunal de Cuentas, al tiempo que "proporcionan un marco general» que permite fijar de manera detallada los procedimientos y las prácticas que deben seguirse para la planificación y la ejecución de las distintas tareas de fiscalización, así como para la elaboración de los informes correspondientes, siendo de aplicación tanto a la "auditoría financiera (incluidas las fiscalizaciones relativas a la declaración de fiabilidad-DAS ${ }^{36}$ )", como a los "controles de la buena gestión financiera" realizados por el Tribunal ${ }^{37}$.

El resultado del examen de las cuentas de la totalidad de los ingresos y gastos anteriormente expresados se concretará, de un lado, en la presentación por el Tribunal de Cuentas Europeo al Parlamento y al Consejo, de una "declaración sobre la fiabilidad de las cuentas y la legalidad y regularidad de las operaciones correspondientes, que será publicada en el "Diario Oficial de la Unión Europea»", y que "podrá completarse con observaciones específicas sobre cada uno de los ámbitos principales de la actividad de la Unión", como ya se recoge en el artículo 248.1 del Tratado CE según las modificaciones introducidas por el Tratado de Niza.

De otra parte, como resultado del control de las cuentas de la Unión, el Tribunal «elaborará un informe anual después del cierre de cada ejercicio", que será remitido "a las instituciones y publicado en el

\footnotetext{
${ }^{36}$ Abreviatura del francés Déclaration D'Assurance

37 Vid. http://www.eca.eu.int./audit_approach/policies/docs/caps_es.pdf.
} 
"Diario Oficial de la Unión Europea», junto con las respuestas de estas instituciones a las observaciones" del Tribunal. Además, podrá "presentar en cualquier momento sus observaciones, que podrán consistir en informes especiales, sobre cuestiones particulares".

Todos ellos aspectos recogidos en la regulación del Tribunal de Cuentas Europeo según las reformas introducidas por el Tratado de Niza en el artículo 248.4 del Tratado CE, así como la exigencia de que dichos informes anuales y especiales deberán ser aprobados "por mayoría de los miembros" que componen el Tribunal de Cuentas, y la previsión de que - con los requisitos y las condiciones que se establezcan en su Reglamento Interno-, se puedan crear en su seno "salas" para "aprobar determinados tipos de informes» (artículo III-384.4, párrafo 3 del TICE). Unas mayorías que también se exigen de forma idéntica en los textos vigentes para la aprobación de los dictámenes que puede emitir el Tribunal "a instancia de una de las demás instituciones» (artículo III-384.4, párrafo segundo, in fine, del mismo texto).

En la práctica, a través del ejercicio de esta labor fiscalizadora, el Tribunal de Cuentas Europeo ha venido participando en el denominado por J. Darras y V. Schmitt, "control político" del Presupuesto, a partir de su diferenciación entre un "control esencialmente material y técnico", ejercido por el Tribunal de Cuentas, y un "control político" desarrollado por el Parlamento, con el que el "control externo" se encuentra necesaria aunque "indirectamente» relacionado, lo que hace de estas instituciones dos "elementos clave del control de las finanzas comunitarias ${ }^{38}$, de ahí que, en términos genéricos, el párrafo cuarto del artículo III-384.4 del TICE reconozca al Tribunal de Cuentas la labor de "asistir» al Parlamento Europeo y al Consejo en el ejercicio de su función de control de la ejecución del Presupuesto, como ya se recoge en el artículo. 248.4 del Tratado CE según las reformas introducidas por el Tratado de Niza.

En efecto, siendo la Comisión la institución encargada de la ejecución del Presupuesto en cooperación con los Estados miembros, «bajo su propia responsabilidad y dentro del límite de los créditos autorizados" (artículo III-407 del TICE), como ya se recoge en el primer párrafo del artículo 274 del Tratado CE, también estará obligada a "presentar» cada año al Parlamento Europeo y al Consejo "las cuentas del ejercicio cerrado relativas a las operaciones del Presupuesto", además de "re-

38 DARRAS, J., y SchMITT, V. : “Contrôle des Finances des Communautés Européennes", en Dictionnaire encyclopédique des finances publiques. Paris, Económica, 1991, pp. 491-492. 
mitir» a dichas instituciones "un balance financiero del activo y pasivo de la Unión" y un "informe de evaluación de las finanzas de la Unión» basado en los resultados obtenidos, concretamente, "en relación con las indicaciones dadas por el Parlamento Europeo y el Consejo en virtud del artículo III-409»(artículo III-408 del TICE), modificando sólo en parte el contenido del vigente ar. 275 del Tratado CE.

De este modo, el Parlamento Europeo, "por recomendación del Consejo", aprobará "la gestión de la Comisión en la ejecución del Presupuesto" (artículo III-409, párrafo primero del TICE), en un acto de aprobación que es conocido como "decisión de descargo" y sobre el que conviene subrayar la desaparición del requisito de la «mayoría cualificada" de los miembros del Parlamento Europeo, exigida en el apartado primero del artículo 276 del Tratado CE, circunstancia que, de acuerdo con lo dispuesto por el artículo III-338 del TICE, significa, sencillamente, la aprobación de la gestión "por mayoría de los votos emitidos".

A tal efecto, en una redacción similar a la contenida en el mencionado artículo 276, apartado primero, del Tratado CE, el Parlamento Europeo examinará "después del Consejo", los siguientes documentos: "las cuentas, el balance financiero y el informe de evaluación mencionados en el artículo III-408, el informe anual del Tribunal de Cuentas, junto con las respuestas de las instituciones controladas a las observaciones del Tribunal de Cuentas, la declaración de fiabilidad a que se refiere el segundo párrafo del apartado 1 del artículo III-384 y los informes especiales pertinentes del Tribunal de Cuentas" (artículo III-409.1 del TICE).

Por último, en una redacción que, en parte, recuerda contenidos de los párrafos 2 y 3 del artículo 276 del Tratado CE, se contempla la posibilidad de que antes de aprobar la gestión de la Comisión, "o con cualquier otra finalidad enmarcada en el ejercicio de las atribuciones de ésta en materia de ejecución del Presupuesto", el Parlamento Europeo podrá pedir la comparecencia de la Comisión «en relación con la ejecución de los gastos o el funcionamiento de los sistemas de fiscalización financiera», debiendo la Comisión facilitar al Parlamento Europeo, a instancia de éste, "toda la información necesaria" (párrafo 2, artículo III-409 del TICE).

Del mismo modo, la Comisión "hará todo lo necesario" para "dar curso" a las observaciones que acompañen "las decisiones" de aprobación de la gestión y las demás observaciones del Parlamento Europeo sobre la ejecución de los gastos, así como a los comentarios que acompañen "las recomendaciones de aprobación" de la gestión adoptadas por el Consejo (párrafo 3, artículo III-409 del TICE). 
La Comisión, en cualquier caso, deberá informar "a instancia del Parlamento Europeo o del Consejo", de las medidas adoptadas "a raíz de dichas observaciones y comentarios" y, en particular, de las instrucciones impartidas a los servicios encargados de la ejecución del Presupuesto. Dichos informes "se enviarán también al Tribunal de Cuentas" (párrafo 4, artículo III-409 del TICE).

En última instancia, se ha de subrayar la inclusión en el TICE de la presencia del Tribunal de Cuentas también en otro momento sumamente significativo de la gestión presupuestaria, como lo es la elaboración de la "ley europea" que establecerá tanto "las normas financieras por las que se determinarán, en particular, las modalidades de adopción y ejecución del Presupuesto, así como las referentes a la rendición y censura de cuentas" [(artículo III-412, apartado 1 a)] como "las normas por las que se organizará el control de la responsabilidad de los agentes financieros, en particular de los ordenadores de pagos y de los contables" [(artículo III-412, apartado 1 b)], dado que en ambos casos "se adoptará previa consulta al Tribunal de Cuentas» ${ }^{39}$.

b) La naturaleza jurídica de los informes del Tribunal de Cuentas Europeo

Ante la falta de referencias explícitas en los Tratados constitutivos de las Comunidades Europeas a la naturaleza jurídica de los informes del Tribunal de Cuentas, la concreción de este aspecto ha quedado encuadrada en el ámbito de los pronunciamientos del Tribunal de Justicia de la Unión Europea.

En efecto, el Tribunal de Justicia de las Comunidades Europeas no se ha pronunciado hasta fechas recientes acerca de las funciones del Tribunal de Cuentas Europeo. Sin embargo, aunque en las Sentencias Partie écologiste "Les Verts" contra Parlement Européen, de 23 de abril de $1986^{40}$, y en la Sentencia Landbrugsministeriet-EF-Direktoratet contra Steff-Houlberg Export I/S y otros, de 12 de mayo de $1998^{41}$, el Tribunal

39 La misma exigencia de "previa consulta» al Tribunal de Cuentas Europeo se contempla e el artículo III-415.4 del TICE para la adopción de "la ley o la ley marco europea" que establezca las medidas necesarias en los ámbitos de la prevención y lucha contra el fraude que perjudique a los intereses financieros de la Unión, «con miras a ofrecer una protección eficaz y equivalente en los Estados miembros y en las instituciones, órganos y organismos de la Unión".

40 Aff. 294/83, Rec. 1986-4, pp. 1339 y ss.

41 Aff. C-366/95, Rec. 1998-5, pp. I-2661 y ss. 
de Justicia se pronunciaba "obiter dicta" al respecto, será la Sentencia Ismeri Europa Srl/Cour des Comptes, de 10 de julio de 200142, la primera del Tribunal de Justicia relativa a las competencias del Tribunal de Cuentas Europeo ${ }^{43}$.

Este último pronunciamiento tiene su origen en el informe especial n. ${ }^{\circ}$ 1/96, de 30 de mayo de 1996, del Tribunal de Cuentas, relativo a los Programas MED y publicado en el Diario Oficial de las Comunidades Europeas de 19 de agosto de 1996, en el que el Tribunal de Cuentas cuestionaba diferentes aspectos de la gestión de los Programas MED, destacando especialmente la confusión de intereses en el sistema global de gestión.

Concretamente, el Tribunal de Cuentas señalaba que de los cuatro administradores de la "Agence pour les Réseaux Transméditerranéens", asociación belga sin ánimo de lucro creada por la Comisión y encargada de la administración y la gestión financiera de los Programas MED, dos eran directivos de oficinas de asistencia técnica a las que se había concedido algún contrato para el seguimiento de los programas a cuya elaboración habían contribuido en el marco del Consejo de Administración de la Agencia.

En relación con dicho informe especial, el Parlamento Europeo adoptó el 17 de julio de 1997 una resolución en la que se recogían los hechos constatados por el Tribunal de Cuentas, destacaba el carácter ejemplar del asunto e invitaba a la Comisión a adoptar medidas enérgicas para evitar que se reprodujeran situaciones análogas.

Tras reconocer el Tribunal de Primera Instancia que los hechos mencionados en el Informe $n .{ }^{\circ} 1 / 96$, revelaban un conflicto de intereses y que el Tribunal de Cuentas no había incurrido en un comportamiento ilícito al denunciarlos, así como que los mismos habían sido probados materialmente e interpretados de manera correcta, desestimando el recurso planteado, los recurrentes solicitaron al Tribunal de Justicia la anulación de dicha Sentencia a través de un recurso de casación.

42 Aff. C-315/99 P, Rec. 2001, pp. I-5281 y ss.

${ }^{43}$ Ciertamente, en las Sentencias H. Contra Tribunal de Cuentas de las Comunidades Europeas (Aff.C-416/92 Rec. 1994-5, pp. I-1741 y ss.) y en la Sentencia Henri Maurissen y Union Sindícale contra Tribunal de Cuentas de las Comunidades Europeas (Aff. Jtes. 193 y 194/87, Rec. 1989-5, pp. 1045 y ss.), el Tribunal de Justicia reconocía la posibilidad de presentar un recurso de anulación contra una «decisión administrativa" del Tribunal de Cuentas.

${ }^{44}$ INGHELRAM, J.: "L'arret Ismeri:Quelles conséquences pour la Cour des Comptes européenne?». Cahiers de Droit Européen, n.os 5-6, 2001, pp. 726-727. 
En las Conclusiones presentadas por el Abogado General, Sr. RuizJarabo Colomer, se refería al entonces artículo 173 del Tratado CE afirmando que "el legislador constituyente comunitario ha querido que la actividad de todas las instituciones estuviera sujeta al control jurisdiccional del Tribunal de Justicia cuando ésta produzca efectos jurídicos frente a terceros", de tal modo que, siendo el Tribunal de Cuentas Europeo una "institución comunitaria, nada impide admitir recursos de anulación contra sus actos" (punto 44). De hecho, afirmaba, en anteriores pronunciamientos (Sentencia de 10 de febrero de 1983, Luxemburgo contra Parlamento Europeo, y Sentencia de 23 de abril de 1986, Los Verdes contra Parlamento Europeo), el Tribunal de Justicia «ha reconocido su competencia para conocer de un recurso de anulación" presentado al amparo del artículo 173 del Tratado contra un acto del Parlamento destinado a producir efectos jurídicos frente a terceros, sentando al respecto una jurisprudencia que ha permanecido inalterada (punto 38).

Según esta jurisprudencia, serían impugnables «todos los actos que produzcan efectos jurídicos vinculantes y que puedan incidir sobre los intereses del recurrente, modificando su posición jurídica" (punto 45), en cuyo caso, afirmaba, "la forma del acto no tiene importancia" (punto 46). Por el contrario, el Tribunal de Justicia ha considerado no admisibles los recursos contra "actos no susceptibles de constituir, por sí mismos, derechos y obligaciones en relación con terceros", como es el caso de "mandatos de carácter interno, que no producen efectos fuera de la esfera de la institución que produce el acto", ni «actos precedentes o sucesivos a la decisión que concluye un procedimiento complejo", así como tampoco "actos que se limitan a reproducir o a confirmar actos precedentes o los de mera ejecución" (punto 47).

Desde tales premisas, el Abogado General se cuestionaba acerca de la posibilidad de que el Tribunal de Cuentas Europeo, como institución comunitaria, pudiera emanar actos destinados a producir efectos jurídicos frente a terceros que, en tal medida, puedan ser susceptibles de recurso ante el Tribunal de Justicia. A tal efecto, analizaba la naturaleza jurídica de la actividad del Tribunal de Cuentas, considerando que éste desarrolla una doble función, de control y consultiva. En ejercicio de la primera, afirmaba, "controla las cuentas de la Comunidad, examinando todos los ingresos y gastos". Un examen que tiene por objeto tanto "la legitimidad y la regularidad de unos y otros" como "la buena gestión financiera", con el fin de "denunciar cualquier irregularidad", y que se traduce en "informes y observaciones". La segunda de las funciones, a su juicio, "es de carácter consultivo, y se manifiesta en dictámenes" (punto 49). 
No obstante, reconocía que la actividad de control del Tribunal de Cuentas "forma parte de un proceso mucho más amplio: el del control de la ejecución del presupuesto de la Comunidad - que corresponde al Consejo y al Parlamento europeo-, el cual se articula en un procedimiento de rendimiento de cuentas o de "descargo", en relación con el cual el Tribunal de Cuentas, a través de sus informes y observaciones, desarrolla una función imprescindible, pero auxiliar: la de asistir a las mencionadas instituciones, aportando su propia opinión acerca de la ejecución del presupuesto" (punto 51).

Por todo ello, concluía el Abogado General que un «informe» del Tribunal de Cuentas «no constituye un acto idóneo para producir efectos jurídicos frente a terceros", de tal modo que, "según la jurisprudencia del Tribunal de Justicia, no puede ser impugnado a través de recurso de anulación» (punto 52).

Una conclusión del Abogado General que si bien no es desarrollada en profundidad por la Sentencia del Tribunal de Justicia, viene a ser asumida indirectamente en el punto 29 de la misma, al afirmar que "la adopción y publicación de los informes del Tribunal de Cuentas no son decisiones que afecten directamente a los derechos de las personas que se mencionan en ellos".

Esta interpretación acerca de la naturaleza jurídica de los informes del Tribunal de Cuentas Europeo debe entenderse válida, en opinión de J. Inghelram, tanto para un recurso de anulación presentado "por una "persona" " a la que el Tribunal de Cuentas se refiera explícitamente, como a un "recurso de anulación presentado por una institución comunitaria», pues, afirma, resulta difícil apreciar los efectos jurídicos que pueda producir para una institución comunitaria un informe del Tribunal de Cuentas que describa los hechos y formule recomendaciones. De modo que, en todo caso, considera que son "las observaciones que acompañan las decisiones de descargo, las observaciones del Parlamento Europeo relativas a la ejecución de los gastos y los comentarios que acompañan las recomendaciones de descargo adoptadas por el Consejo, las que tienen vocación de producir, en cierta medida, efectos jurídicos para la Comisión ${ }^{44}$.

En todo caso, siguiendo la interpretación amplia que el Tribunal de Justicia ha venido realizando acerca del control jurisdiccional de los actos de las instituciones europeas, en el TICE se reconoce la competencia del Tribunal de Justicia para controlar la legalidad de "los actos del

45 Vid. al respecto, entre otros, LeLONG, P.: "La Cour des Comptes des Communautés européennes: sa mission, son bilan», op. cit., pp. 36-37. 
Parlamento Europeo y del Consejo Europeo destinados a producir efectos jurídicos frente a terceros", así como "la legalidad de los actos de los órganos u organismos de la Unión destinados a producir efectos jurídicos frente a terceros" (artículo III-365.1). De este modo, se altera, aunque no sustancialmente, el contenido del vigente párrafo primero del artículo 230 del Tratado CE, puesto que tan sólo se añade al control de legalidad de los actos de diferentes instituciones el de los "actos de los órganos $\mathrm{u}$ organismos de la Unión destinados a producir efectos jurídicos frente a terceros".

A tales efectos, el Tribunal de Justicia de la Unión Europea, afirma el apartado segundo del mismo precepto del TICE, "será competente para pronunciarse sobre los recursos por incompetencia, vicios sustanciales de forma, violación de la Constitución o de cualquier norma jurídica relativa a su ejecución, o desviación de poder, interpuestos por un Estado miembro, el Parlamento Europeo, el Consejo o la Comisión", manteniendo, prácticamente en todos sus términos, la redacción que contiene el artículo 230, párrafo segundo, de la versión consolidada en el Tratado de Niza, que ya había incluido al Parlamento Europeo entre las instituciones legitimadas para interponer los recursos a que se hace referencia.

En las condiciones mencionadas, el Tribunal de Justicia también será competente para pronunciarse "sobre los recursos interpuestos por el Tribunal de Cuentas, el Banco Central Europeo y el Comité de las Regiones con el fin de salvaguardar las prerrogativas de éstos (apartado 3 del mismo precepto del TICE), introduciendo al Comité de las Regiones como única novedad respecto de la versión consolidada en el Tratado de Niza.

Por último, en las condiciones anteriores, toda persona física o jurídica podrá interponer recurso "contra los actos de los que sea destinataria o que la afecten directa e individualmente y contra los actos reglamentarios que la afecten directamente y que no incluyan medidas de ejecución" (artículo III-365, apartado 4 del TICE), modificando el contenido del párrafo cuarto del artículo 230 del Tratado CE, donde el recurso se puede interponer contra "las decisiones de las que sea destinataria", y contra las decisiones que, "aunque revistan la forma de un reglamento o de una decisión dirigida a otra persona, le afecten directa e individualmente", excluyendo de modo expreso a todos los actos reglamentarios "que no incluyan medidas de ejecución".

Una regulación que, en todo caso, parece mantenerse en la línea de la jurisprudencia marcada por el Tribunal de Justicia sobre la naturaleza jurídica de los informes del Tribunal de Cuentas Europeo, aunque se 
ha de subrayar, de cualquier modo, que la redacción del artículo III-365 del TICE refuerza el control de legalidad por parte del Tribunal de Justicia, al incluir dentro de su capacidad de control la legalidad de los «actos de los órganos u organismos de la Unión destinados a producir efectos jurídicos frente a terceros".

\section{CONCLUSIONES}

Ante todo, se ha de destacar que la incorporación del Tribunal de Cuentas Europeo al entramado institucional de la Unión Europea ha sido progresiva, no sólo desde la perspectiva de su propia configuración jurídica en los Tratados fundacionales, sino también en el reconocimiento de sus competencias, de modo que, en la actualidad, no existe discusión alguna acerca de su consideración como institución de la Unión Europea.

No obstante, en el proceso de configuración jurídica del Tribunal de Cuentas iniciado con el Tratado de Bruselas de 1975, ha tenido una importancia decisiva el también progresivo reforzamiento del papel del Parlamento Europeo en materia presupuestaria, de ahí que resulte especialmente significativo el hecho de que el artículo III-409 del Tratado por el que se instituye una Constitución para Europa haya suprimido la exigencia de "mayoría cualificada" del Parlamento Europeo para aprobar la gestión de la Comisión en la ejecución del Presupuesto, como reconoce el artículo 276.1 del Tratado C.E., circunstancia que, sin duda, redundará en el ejercicio de un "control político" del Parlamento sobre las finanzas europeas.

En todo caso, con carácter general, los rasgos jurídicos esenciales que ha llegado a adquirir el Tribunal de Cuentas en el ordenamiento europeo han sido mantenidos por el constituyente europeo en la regulación que incorpora el Tratado por el que se instituye una Constitución para Europa, si bien parece posible identificar en la regulación del Tribunal de Cuentas contenida en el TICE una "deliberada" voluntad del constituyente europeo de eliminar las mayorías reforzadas en el Consejo que la actual regulación contempla.

En efecto, el artículo III-384 del TICE guarda silencio respecto de la mayoría requerida en el Consejo para aprobar el Reglamento Interno elaborado por el Tribunal de Cuentas, mientras que el artículo 248.4, in fine, del Tratado CE, según la redacción incorporada por el Tratado de Niza, establece al respecto una "mayoría cualificada" del mismo. Asimismo, el artículo III-385.2 del TICE exige la adopción de la lista de miembros del Tribunal de Cuentas mediante una "decisión europea», 
modificando así la "mayoría cualificada» del Consejo exigida al efecto por el Tratado de Niza que, a su vez, reducía la exigencia de "unanimidad" a la que hacía referencia el artículo 247.3 de la versión consolidada del Tratado de Ámsterdam.

De otro lado, el TICE incorpora ciertas novedades en la regulación del status de los miembros del Tribunal de Cuentas Europeo remitiendo, en su caso, al reglamento interno del Tribunal de Cuentas la concreción de aspectos tales como las condiciones de empleo de los miembros del Tribunal, así como los sueldos, dietas, pensiones y cualquier otro emolumento de carácter retributivo, que actualmente se encuentra regulado en el artículo 247.8 del Tratado CE.

Un status de los miembros del Tribunal de Cuentas Europeo que resulta también afectado por la omisión por el TICE de la previsión contenida en el artículo 247 del Tratado CE, en virtud de la cual son de aplicación a los miembros del Tribunal de Cuentas las disposiciones del Protocolo sobre privilegios e inmunidades aplicables a los jueces del Tribunal de Justicia.

Por lo demás, la regulación que incorpora el Tratado por el que se instituye una Constitución para Europa respecto de las funciones de esta institución de la Unión reproduce, en términos globales, los caracteres que esta institución europea había alcanzado con los Tratados de Maastricht (1992), Ámsterdam (1997) y Niza (2001), manteniendo, de este modo, los mismos "silencios" y las mismas "imprecisiones" a las que la doctrina se refería en relación a esta regulación ${ }^{45}$, especialmente en lo referente al sistema a través del cual se articulan las relaciones entre el Tribunal de Cuentas Europeo y las instituciones u órganos homólogos de los Estados miembros.

No obstante, debe subrayarse el requisito de la consulta previa al Tribunal de Cuentas exigido para la elaboración de la "ley europea" que establecerá las normas financieras por las que se determinarán las modalidades de adopción y ejecución del Presupuesto, así como las referentes a la rendición y censura de cuentas, prevista en el artículo III412, apartado 1 a) del TICE, y para la "ley europea» que establezca las normas por las que se organizará el control de la responsabilidad de los agentes financieros, en particular de los ordenadores de pagos y de los contables, contemplada en el artículo III-412, apartado 1 b) del TICE.

En última instancia, la regulación del TICE parece situarse en la línea establecida por el Tribunal de Justicia respecto de la naturaleza jurídica de los informes del Tribunal de Cuentas Europeo, al no ofrecer significativas novedades en relación con la actual regulación de las competencias del Tribunal de Justicia contenida en el artículo 230 del Tratado CE. 